\title{
AVALIAÇÃO DA GERMINAÇÃO EM DIFERENTES TEMPERATURAS E SUBSTRATOS E MORFOLOGIA DO FRUTO, SEMENTE E PLÂNTULA DE Sebastiania brasiliensis
}

\author{
Marcos Vinícius Martins Bassaco ${ }^{1}$, Antonio Carlos Nogueira ${ }^{2}$, Nelson Luiz Cosmo ${ }^{3}$ \\ ${ }^{1}$ Eng. Florestal, M.Sc., ULT, Jaguariaíva, PR, Brasil - marcos.bassaco@ hotmail.com \\ ${ }^{2}$ Eng. Florestal, Dr., Depto. de Ciências Florestais, UFPR, Curitiba, PR. Brasil - nogueira@ufpr.br \\ ${ }^{3}$ Eng. Florestal, Dr., Depto. de Pesquisa e Monitoramento, SEMMA, Curitiba, PR, Brasil - ncosmo@gmail.com
}

Recebido para publicação: 24/05/2013 - Aceito para publicação: 10/02/2014

\begin{abstract}
Resumo
Em virtude da carência de trabalhos com sementes florestais nativas, este estudo objetivou conhecer as principais características morfológicas e germinativas de Sebastiania brasiliensis (Spreng.). Na descrição morfológica, foram observadas as características internas e externas dos frutos e sementes e o desenvolvimento inicial da plântula. Os testes de germinação foram realizados em dois substratos (areia e vermiculita) e sob três temperaturas $\left(25^{\circ} \mathrm{C}, 30^{\circ} \mathrm{C}\right.$ e $\left.35^{\circ} \mathrm{C}\right)$. O delineamento utilizado foi o inteiramente casualizado, em esquema fatorial $2 \times 3$, com cinco repetições, calculando-se a porcentagem de germinação, o índice de velocidade de germinação (IVG) e o tempo médio. No estudo da morfologia, observou-se que os frutos são do tipo cápsula com três cocas (uma semente/coca). A semente é endospérmica, a testa é do tipo glabra, possuindo uma coloração marrom com pequenas manchas claras. $\mathrm{O}$ embrião é axial, foliáceo e espatulado. As plântulas têm desenvolvimento fanerocotiledonar, epígeo, com cotilédones foliáceos fotossintetizantes. Nos testes de germinação, as sementes submetidas à temperatura de $30^{\circ} \mathrm{C}$ e em vermiculita germinaram $86 \%$, com IVG de 7,05 e melhor tempo médio de 3,39 na temperatura de $25^{\circ} \mathrm{C}$ em substrato vermiculita. Conclui-se que a temperatura de $30^{\circ} \mathrm{C}$ no substrato vermiculita propiciou a melhor germinação, e a morfologia indica características típicas para o gênero.

Palavras-chave: Branquilho-leiteiro; análise germinativa; caracterização morfológica.
\end{abstract}

\begin{abstract}
Germination evaluation in distinct temperatures and substrates, and morphology of fruit, seed and seedling of Sebastiania brasiliensis. Due the lack of surveys/researches regarding native forest seeds, this study aimed to identify the main morphological and germination features/patterns of Sebastiania brasiliensis (Spreng.). For the morphological description, it was observed the internal and external features of fruits and seeds and early seedling development. We tested germination in two substrates (sand and vermiculite) and three temperatures $\left(25^{\circ} \mathrm{C}, 30^{\circ} \mathrm{C}\right.$ and $\left.35^{\circ} \mathrm{C}\right)$. The experimental design was completely randomized in a $2 \times 3$ factorial with five replications, aiming to calculate the percentage, rate index and average time of germination. The fruit is a capsule with three cokes (one seed per coke). The seed is endospermic; testa is glabrous, brown with small spots. The axial embryo is foliaceous and spatulate. Seedlings have phanerocotylar epigeal development with foliaceous photosynthetic cotyledons. Seeds planted in vermiculite under $30^{\circ} \mathrm{C}$ of temperature revealed the best germination (86\%), and an IVG of 7.05 ; the best average time was 3.39 at $25^{\circ} \mathrm{C}$ in vermiculite. As conclusion, vermiculite with $30^{\circ} \mathrm{C}$ of temperature led to better germination, and the morphology indicates typical characteristics for the genus Sebastiania.

Keywords: Branquilho-leiteiro; germination analysis; morphological characterization.
\end{abstract}

\section{INTRODUÇÃO}

As sementes, para germinar e propiciar o crescimento do embrião, precisam de algumas condições apropriadas, como disponibilidade de água, temperaturas adequadas, oxigênio e luz (CARVALHO; NAKAGAWA, 1983; BEWLEY; BLACK, 1994). Embora os eventos fisiológicos de germinação sejam similares entre as espécies, há diferenças importantes quanto às condições ideais, que 
são determinadas por fatores hereditários e ambientais e estão associadas às características ecofisiológicas da espécie. Assim, espécies de um grupo ecológico podem necessitar de condições diferentes de espécies de outros grupos para expressar seu potencial germinativo (VELÁSQUEZ, 2002; SILVA et al., 2007).

No intuito de ser minimizarem os efeitos do ambiente e determinar o potencial germinativo de determinada espécie, é importante que se realizem os testes de germinação em condições controladas, como as propiciadas por laboratórios de sementes, onde tem-se o controle de temperatura, substrato, água e luz (PIÑA-RODRIGUES et al., 2004). Esse controle propiciado em laboratório, além de favorecer os efeitos citados, também se torna importante para avaliar a qualidade de um lote de sementes, seja para valorar as sementes para comercialização, seja para criar métodos padronizados que forneçam dados precisos, confiáveis e sejam passíveis de replicação em outros laboratórios (LIMA JUNIOR, 2010).

Dessa forma, a temperatura e o substrato são dois dos fatores laboratoriais mais importantes que controlam a germinação das sementes, e pesquisas sobre o efeito deles na germinação de sementes de espécies florestais nativas do Brasil vêm sendo desenvolvidas desde o início da década de 1980 (SILVA et al., 2007).

A temperatura tem importante influência sobre o processo germinativo, tanto na porcentagem como na velocidade de germinação. A temperatura influencia na velocidade de absorção de água e nas reações bioquímicas que determinam todo o processo de germinação. A germinação será tanto mais rápida e o processo mais eficiente quanto maior for a temperatura, até certo limite (CARVALHO; NAKAGAWA, 1983).

Nesse sentido, podem-se identificar três pontos críticos de temperatura para germinação: a temperatura mínima, abaixo da qual não há germinação visível em período razoável de tempo; a temperatura máxima, acima da qual não há germinação; e a temperatura ótima, na qual o número máximo de sementes germina num período de tempo mínimo. Essas temperaturas são chamadas de temperaturas cardinais de germinação (BEWLEY; BLACK, 1994). A temperatura ótima para a germinação da maioria das sementes encontra-se na faixa entre $15^{\circ} \mathrm{C}$ e $30^{\circ} \mathrm{C}$ e a máxima na faixa de $35^{\circ} \mathrm{C}$ a $40{ }^{\circ} \mathrm{C}$ (POPINIGIS, 1977; TOLEDO; MARCOS FILHO, 1977; CARVALHO; NAKAGAWA, 1983; MALAVASI, 1988; OLIVEIRA, 2007).

Outro importante fator é o substrato, por ser o meio de que a semente dispõe para germinar e por ter a função de manter a umidade, preservando as condições ideais para que esse processo ocorra. É prioritário que não ofereça barreiras (físicas) ao crescimento das plântulas e seja inerte (PIÑARODRIGUES; VIEIRA, 1988). Os tipos de substrato mais utilizados, descritos e prescritos nas Regras de Análise de Sementes (RAS), são: papel toalha, papel filtro, papel mata-borrão e areia (BRASIL, 2009). Portanto, para a escolha do substrato, deve ser levado em consideração o tamanho da semente, sua exigência com relação à quantidade de água, sua sensibilidade ou não à luz e a facilidade que o mesmo oferece para a realização das contagens e para a avaliação das plântulas (POPINIGIS, 1977; FIGLIOLIA et al., 1993).

A areia é indicada para todos os tipos de sementes, principalmente para as espécies mais sensíveis ao ressecamento e para as sementes grandes com germinação lenta. Como desvantagens, esse substrato ocupa muito espaço para o seu armazenamento, é pesado e danifica as caixas plásticas utilizadas para germinação (gerbox) (WILLAN, 1991; FIGLIOLIA; PIÑA-RODRIGUES, 1995).

A vermiculita tem sido o substrato mais empregado em espécies florestais, pelos excelentes resultados demonstrados. Ela não é tão pesada quanto a areia, porém apresenta como desvantagem a necessidade de se utilizarem recipientes de maiores dimensões, que requerem maior volume de substrato (PINÃ-RODRIGUES et al., 2004). Esse substrato é indicado para as sementes que possuem formas esféricas, tais como Esenbeckia leiocarpa Engl. (guarantã), Astronium urundeuva (Fr. Ale.) Engl. (aroeira), Mimosa scabrella Benth. (bracatinga), Ocotea spp., Cryptocarpa spp., Nectandra spp. (canelas) e Cassia spp. (cássias) (FIGLIOLIA et al.,1993).

Uma das formas de facilitar a escolha do substrato ideal para germinação e também auxiliar na interpretação dos testes é o conhecimento prévio da espécie, principalmente no que se refere às características morfológicas da semente e do desenvolvimento da plântula (OLIVEIRA; PEREIRA, 1987).

São relativamente escassas as descrições morfológicas detalhadas dos órgãos reprodutivos e, principalmente, das plântulas de espécies nativas da Floresta Ombrófila Mista, onde Sebastiania brasiliensis (Spreng.) ocorre com maior frequência (REITZ, 1988), embora algumas espécies ocorrentes nessa unidade fitogeográfica tenham sido estudadas por Kuniyoshi (1983), Roderjan (1983), Cosmo et al. (2009, 2010), Gogosz et al. (2010), Rego et al. (2011), Gogosz (2013) e Haliski et al. (2013). 
Estudos dessa natureza são bastante relevantes, em função das implicações da morfologia dos órgãos reprodutivos e das plântulas nos aspectos funcionais e ecológicos (VOGEL, 1980; WRIGHT et al., 2000; IBARRA-MANRÍQUEZ et al., 2001; RESSEL et al., 2004). Segundo Cosmo et al. (2010), o conhecimento da morfologia de espécies nativas é de grande valia para o entendimento de sua autoecologia e distribuição nos diferentes ecossistemas, sendo bastante útil para a ecologia, silvicultura e conservação das espécies arbóreas.

Sebastiania brasiliensis pertence à família Euphorbiaceae e é conhecida vulgarmente por leiteiro-de-folha-fina ou branquilho-leiteiro. Pode ser encontrada como arbusto ou árvore, frequentemente desenvolvendo-se no interior dos capões e dos sub-bosques da Floresta Ombrófila Mista Aluvial, situados em solos úmidos em beira de rios e na restinga arbustiva do litoral, neste caso situada em pequenas depressões (REITZ, 1988).

Procurando preencher essa lacuna, o presente trabalho objetivou descrever a morfologia do fruto, semente e plântula, para auxiliar no entendimento do processo germinativo da espécie, bem como avaliar o comportamento germinativo da Sebastiania brasiliensis em diferentes substratos e temperaturas.

\section{MATERIAL E MÉTODOS}

Os frutos de Sebastiania brasiliensis foram coletados de 15 árvores-matrizes localizadas no Distrito de Guajuvira, município de Araucária, PR, e no Parque Barigui, município de Curitiba, PR. Ambas as localidades encontram-se sob domínio de Floresta Ombrófila Mista Aluvial, no Primeiro Planalto Paranaense. Os frutos coletados foram levados para o Laboratório de Sementes Florestais do Departamento de Ciências Florestais da Universidade Federal do Paraná, onde foi realizado o beneficiamento, conforme segue.

\section{Morfologia dos frutos, sementes e plântulas}

Foram utilizadas 20 unidades, selecionadas aleatoriamente, para descrever e ilustrar morfologicamente as sementes, os frutos e as plântulas. As observações foram realizadas utilizando-se de microscópio estereoscópico e a olho nu.

Para a descrição da morfologia dos frutos, foi observado o tipo de fruto, características do epicarpo (textura, pilosidade, coloração, brilho e deiscência) e do mesocarpo (consistência e coloração). Nas sementes, foram feitas secções transversais e longitudinais com auxílio de bisturi e analisados os seguintes parâmetros: cor, textura, consistência, forma, posição do hilo e da micrópila, presença ou ausência de endosperma e se presente o tipo (identificação com SUDAM III) e a cor. Para o embrião, foram avaliados o tipo, a posição e a forma, a forma e consistência dos cotilédones e a posição do eixo hipocótilo-radícula.

$\mathrm{Na}$ caracterização morfológica das plântulas, foram realizadas ilustrações e analisadas as características da raiz: o tipo, a forma e a coloração; do hipocótilo e do epicótilo: a pilosidade, a forma e a coloração; dos cotilédones e protofilos: a consistência, a textura, a forma, a nervação, a coloração e o tipo de bordo, ápice e base.

A terminologia utilizada foi baseada nos trabalhos de Kuniyoshi (1983), Roderjan (1983), Amorim (1996), Barroso et al. (1999) e Vidal e Vidal (2003).

\section{Germinação}

Foram testados os efeitos de diferentes temperaturas e substratos na germinação de sementes de Sebastiania brasiliensis. Para os testes de substrato, foram utilizadas areia e vermiculita fina, e as temperaturas testadas foram $25^{\circ} \mathrm{C}, 30^{\circ} \mathrm{C}$ e $35^{\circ} \mathrm{C}$; cada combinação teve cinco repetições de 30 sementes.

Procurando manter a sanidade dos substratos, eles foram previamente esterilizados em estufa regulada a $105^{\circ} \mathrm{C} \pm 3{ }^{\circ} \mathrm{C}$ durante 24 horas. Depois dessa operação, o substrato areia passou por duas peneiras: uma de $1 \mathrm{~mm}$ e outra de $0,35 \mathrm{~mm}$. Com o objetivo de se obter uma granulometria média, foram descartados os grânulos retidos na primeira peneira e que passaram pela segunda.

Após o preparo dos substratos, eles foram colocados em gerbox previamente desinfestado com álcool 70\%. Do substrato areia utilizaram-se $300 \mathrm{~g}$, juntamente com $60 \mathrm{ml}$ de água destilada, e do substrato vermiculita foram utilizadas $30 \mathrm{~g}$ de vermiculita e $75 \mathrm{ml}$ de água destilada.

Os gerbox contendo as sementes em superfície foram colocados em germinadores tipo Biomatic regulados nas temperaturas de $25^{\circ} \mathrm{C}, 30^{\circ} \mathrm{Ce} 35^{\circ} \mathrm{C}$. 
Feita a instalação do experimento, iniciou-se a contagem da germinação no dia seguinte até o $14^{\circ}$ dia, quando não ocorreu mais germinação ou as sementes estavam em estado de deterioração. $\mathrm{O}$ critério de avaliação utilizado foi a emissão da radícula com tamanho superior a $2 \mathrm{~mm}$. Posteriormente foi calculada a porcentagem de germinação, o índice de velocidade de germinação (IVG) (MAGUIRE, 1962), o tempo médio de germinação (TM) (LABORIAU, 1983) e a germinação acumulada.

A influência da temperatura e do substrato foi analisada em esquema fatorial $3 \times 2$ (3 temperaturas x 2 substratos) com cinco repetições de 30 sementes. Os dados obtidos para a porcentagem, tempo médio e índice de velocidade de germinação nos experimentos efetuados foram submetidos ao teste de Bartlett, para verificar a homogeneidade das variâncias. Para os casos de variância homogênea, os dados foram submetidos à análise de variância, e as médias comparadas entre si pelo teste de Tukey a 5\% de probabilidade (VIEIRA, 1999).

\section{RESULTADOS E DISCUSSÃO}

\section{Morfologia do fruto}

O fruto de Sebastiania brasiliensis tem forma subglobosa e é composto por três cocos unisseminados, cada um dividido em duas valvas, que se rompem nas margens (deiscência marginal) quando maduros. Considerando a classificação proposta por Barroso et al. (1999), tal fruto se enquadra no tipo esquizocarpáceo tricoco. A superfície do exocarpo é glabra, lisa e brilhante, de coloração verdeclara enquanto imaturo, tornando-se castanho-avermelhado e fosco durante a maturação. As cocas têm o pericarpo dividido em duas zonas distintas bem marcadas: o exocarpo, de cor castanho-escura, e o endocarpo, de coloração castanho-clara no fruto maduro (Figura 1).

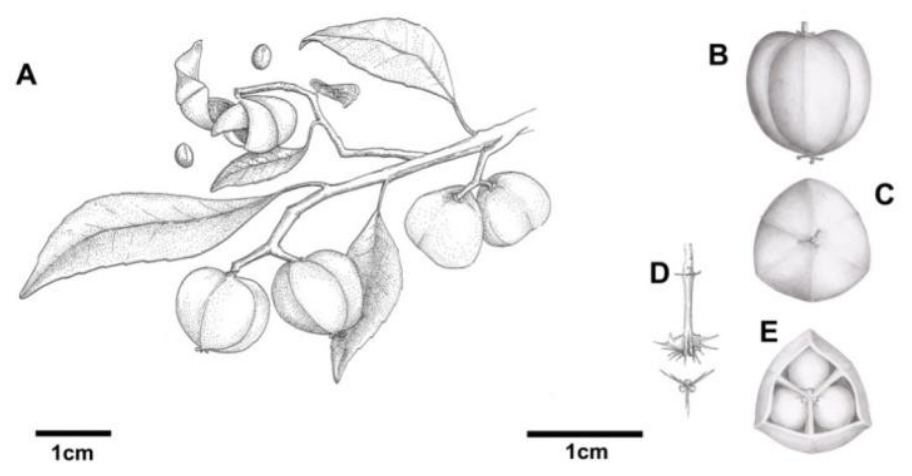

Figura 1. Frutos de Sebastiania brasiliensis. A. ramo com frutos maduros com dispersão autocórica; B e C. fruto em vista lateral e apical; D. detalhe da coluna central onde são inseridas as sementes; E. corte transversal do fruto dividido em três cocas bivalvadas, cada uma contendo uma semente. Ilustração: Nelson Luiz Cosmo.

Figure 1. Fruit of Sebastiania brasiliensis. A. mature branch with fruits with dispersion autochory; B and C. side view in fruit and apical; D. detail of central column where are inserted the seeds; E. cross section of fruit divided into three bivalved cokes, each one containing a seed. Illustration: Nelson Luiz Cosmo.

Segundo Barroso (1984), o tipo de deiscência que ocorre em Sebastiania brasiliensis se dá de forma explosiva (balistocoria) (Figura 1A), resultante da perda de turgor, que causa um encurtamento do fruto não acompanhado pela coluna mediana rígida. $\mathrm{O}$ fruto parte-se levemente na base, separando-se de seu cálice e entre os septos, junto à coluna, abaixo das placentas. As cocas ficam inteiras e no seu orifício ventral a saliência placentar se distende. Na sequência, cada coca fende-se do ápice para a base ao longo da sutura ventral e sobre a nervura média, na porção apical. A tensão gera um movimento violento que libera a semente e separa parcialmente a coca em duas porções (valvas), ligadas pela base. Durante a deiscência, as valvas permanecem ligadas na base ou eventualmente separam-se por completo 
(Figura 1A). Próximo às árvores-matrizes, no momento da dispersão das sementes, é possível ouvir pequenos estalos resultantes do processo de deiscência.

\section{Morfologia da semente}

A semente tem tegumento papiráceo e opaco, testa glabra, ligeiramente áspera e fosca, com superfície marrom-escura com pequenas manchas castanho-claras (Figura 2A).

A semente tem forma elipsoide, com ápice mucronado onde se localiza a micrópila. Na região ventral observa-se o hilo alongado ocupando $2 / 3$ do comprimento da semente. A rafe inicia-se no hilo, chegando até a base. Internamente, na base da semente, observa-se a chalaza (Figura 2B).

A semente é do tipo albuminosa, com reserva de lipídeo no endosperma. O embrião é axial, foliáceo, espatulado, ocupando cerca de 1/4 do volume da semente e tem eixo hipocótilo-radícula bem definido, ocupando metade do comprimento total do embrião. Os cotilédones são foliáceos, peninervados, plano-convexos, cordiformes (Figura 2B e C).
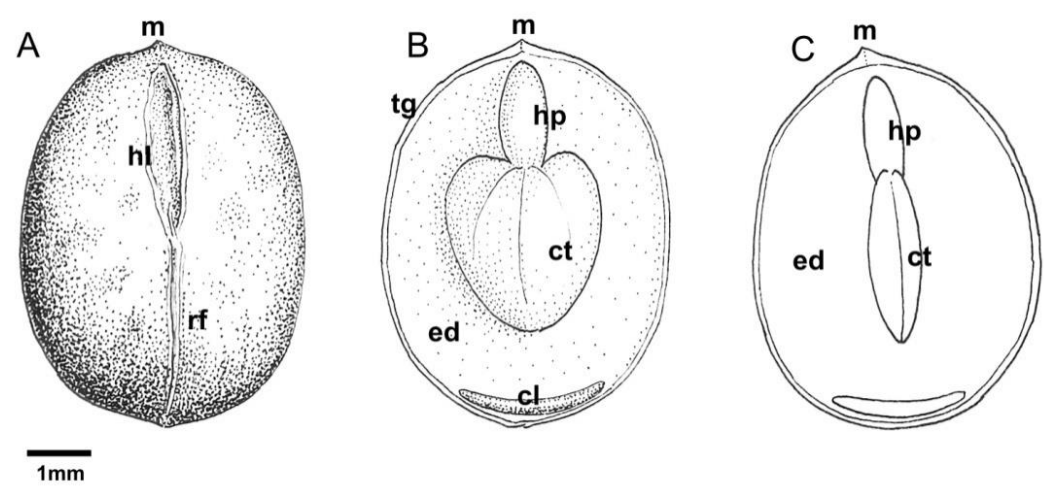

Figura 2. Semente de Sebastiania brasiliensis. A. vista ventral externa; B e C. cortes longitudinais ventral e lateral, respectivamente. (cl: calaza, ct: cotilédones; ed: endosperma; hl: região do hilo; hp: eixo hipocótilo-radicular; m: região da micrópila; rf: rafe; tg: tegumento). Ilustração: Nelson Luiz Cosmo.

Figure 2. Seed of Sebastiania brasiliensis. a. external ventral view, b and c. longitudinal and lateral ventral cuts, respectively. (cl: chalaza, ct: cotyledons; ed: endosperm; hl: region of hilo, hp: hypocotylroot, m: the micropylar end; rf: rafe; tg: integument). Illustration: Nelson Luiz Cosmo.

Comparando-se a semente de Sebastiania brasiliensis com a de Sebastiania commersoniana, descrita por Cosmo et al. (2010), nota-se que o aspecto áspero e fosco da testa e a ausência de carúncula proeminente na semente de Sebastiania brasiliensis são características úteis para a distinção entre as duas espécies, que têm morfologia e distribuição geográfica semelhantes.

\section{Morfologia da plântula}

A germinação fanerocotiledonar iniciou-se por volta do quarto dia após a instalação do experimento, com abertura da micrópila ocasionada pela emergência e crescimento do eixo hipocótiloradícula (Figura $3 \mathrm{~A}$ e $\mathrm{B}$ ).

A partir do segundo dia já é possível distinguir as partes do eixo: hipocótilo curvo, glabro, liso, de cor branca a creme; radícula reta, de cor creme com pelos pouco desenvolvidos e região da coifa acuminada. Delimitando hipocótilo e radícula, nota-se o colo, caracterizado por um sutil espessamento do eixo (Figura 3B e C). No quarto e quinto dia após a protrusão da radícula ocorre a abertura longitudinal do tegumento. Nesse estágio, o endosperma tem forma oval, cor branca e superfície lisa, e os cotilédones ainda não são visíveis. Por volta do sétimo dia, o par de cotilédones continua fechado e oculto pelo endosperma (Figura 3D). Este, à medida que vai sendo consumido, adquire uma consistência gelatinosa, até que se tornem evidentes os cotilédones, de cor verde clara, com nervura central e secundária (Figura 3D).

Após essa fase, o hipocótilo torna-se gradativamente mais ereto e aderido aos cotilédones e observam-se vestígios do endosperma na forma de uma membrana translúcida (Figura 3E). A partir daí os 
cotilédones abrem-se e o epicótilo pode ser notado como uma pequena gema entre eles, que dará origem aos protofilos da plântula (Figura 3F e H). Os cotilédones são glabros e têm cor verde-clara, com nervura central e secundárias evidentes. O início do desenvolvimento do epicótilo coincide com o surgimento das primeiras raízes secundárias, em torno do décimo quarto dia (Figura 3G).

Com o desenvolvimento do epicótilo, inicia-se o desenvolvimento do eofilo a partir do vigésimo quarto dia, com o aparecimento do primeiro par de folhas, sendo estas curto-pecioladas, glabras, levemente discolores, com nervuras pouco evidentes (Figura 3G e I). Tanto o cotilédone quanto o eofilo exsudam látex leitoso quando seccionados.

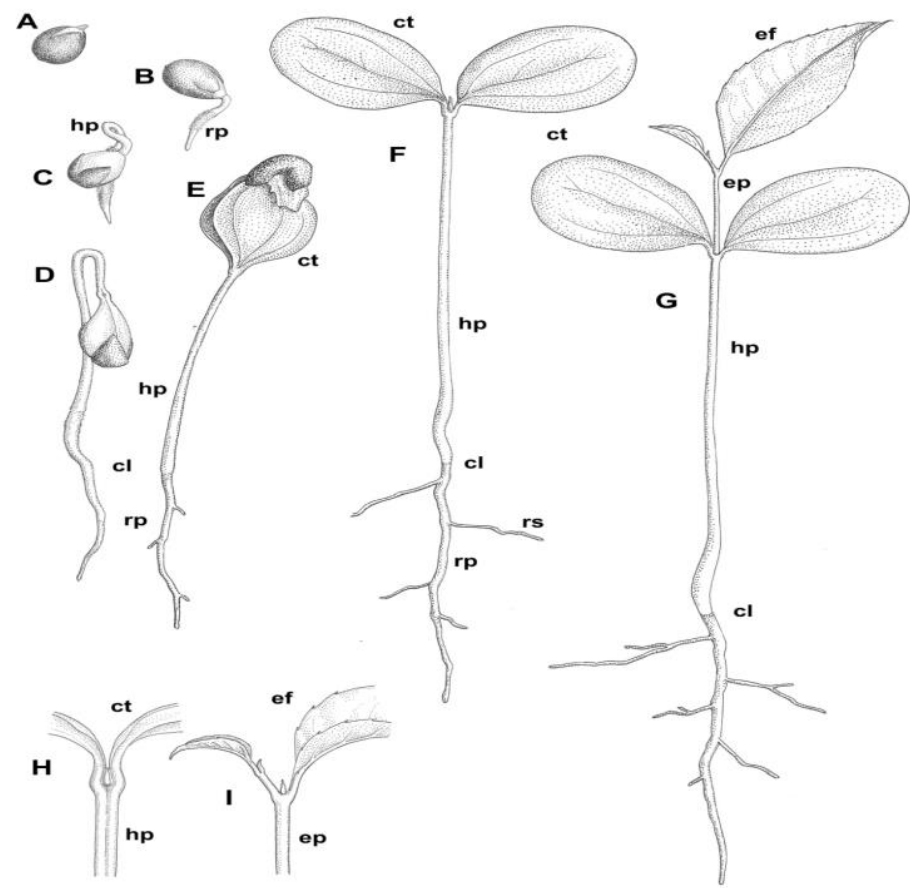

Figura 3. A à G: desenvolvimento da plântula de Sebastiania brasiliensis; H e I: detalhe do nó cotiledonar e do primeiro nó foliar, respectivamente. (cl: região do colo; ct: cotilédone; ef: eofilo; ep: epicótilo; hp: hipocótilo; rp: raiz primária; rs: raiz secundária). Ilustração: Nelson Luiz Cosmo.

Figure 3. A to G: Development of seedling of Sebastiania brasiliensis, H and I: detail of the first knot of cotyledon and knot of leaf, respectively. (cl: neck region; ct: cotyledons and f: eophyll; ep: epicotyl; hp: hypocotyl; rp: primary root; rs: secondary root). Illustration: Nelson Luiz Cosmo.

Comparando tais resultados com as características da plântula de Sebastiania commersoniana, descrita por Cosmo et al. (2010), nota-se que as duas espécies têm desenvolvimento e morfologia semelhantes, exceto pela presença de látex leitoso nos cotilédones e epifilos de Sebastiania brasiliensis, o que não ocorre em Sebastiania commersoniana. Portanto, tal característica pode ser útil para a distinção entre as duas espécies em campo.

O tipo de desenvolvimento da plântula (fanerocotiledonar epígea), bem como a morfologia dos cotilédones e dos eofilos de Sebastiania brasiliensis (foliáceos e fotossintetizantes) são típicos de espécies heliófilas. Tais características representam vantagens estratégicas para as espécies em ambientes abertos, uma vez que proporcionam um rápido desenvolvimento inicial, pouco dependente das reservas da semente, quando comparadas às espécies que possuem cotilédones de reserva (VOGEL, 1980; WRIGHT et al., 2000; IBARRA-MANRÍQUEZ et al., 2001; RESSEL et al., 2004; GOGOSZ, 2013).

\section{Germinação}

Todos os parâmetros apresentaram homogeneidade de variância, verificada por meio do teste de Bartlett, como demonstrado pelo qui-quadrado $\left(\mathrm{X}^{2}\right)$ na tabela 1 . Também verificou-se interação entre 
temperatura e substrato para todas as variáveis (Tabela 1). Com relação à temperatura, o teste de "F" demonstrou haver diferença estatística entre as médias para percentagem de germinação, velocidade de germinação (IVG) e tempo médio (TM), enquanto para o substrato a diferença ocorreu para percentagem e IVG, sendo não significativo para a variável TM (Tabela 1).

Tabela 1. Análise de variância para porcentagem de germinação $(\% \mathrm{G})$, índice de velocidade de germinação (IVG) e tempo médio (TM) de germinação em sementes de Sebastiania brasiliensis em diferentes temperaturas e substratos.

Table 1. Variance analysis for germination percentage $(\% \mathrm{G})$, speed germination index (IVG) and germination average time (TM) for Sebastiania brasiliensis seeds at different temperatures and substrates.

\begin{tabular}{ccccc}
\hline \multirow{2}{*}{ Fonte de variação } & \multirow{2}{*}{ G.L } & \% G & QM & IVG \\
\cline { 3 - 5 } & 2 & $337,8^{* *}$ & $9,1^{* *}$ & $7,2^{*}$ \\
\hline Temperatura & 1 & $1517,0^{* *}$ & $27,1^{* *}$ & $0,1^{\text {ns }}$ \\
Substrato & 2 & $717,0^{* *}$ & $4,9^{* *}$ & $10,7^{* *}$ \\
\hline Temp. X subs. & 5 & $725,3^{* *}$ & $11,0^{* *}$ & $11,0^{* *}$ \\
\hline Trat. & 24 & 19,8 & 0,3 & 0,3 \\
\hline Resíduo & & 6,54 & 12,71 & 12,71 \\
Coef. Variação \% & $6,78^{\text {ns }}$ & $11,33^{\text {ns }}$ & $11,33^{\text {ns }}$ \\
$\chi^{2}$ & & & &
\end{tabular}

*significativo a $\alpha<0,05 ; * *$ significativo a $\alpha<0,01 ;{ }^{\mathrm{ns}}$ não significativo.

Para o substrato areia, a maior percentagem de germinação foi obtida nas temperaturas de $25{ }^{\circ} \mathrm{C}$ e $30{ }^{\circ} \mathrm{C}$, não havendo diferença estatística entre elas, com $66,7 \%$ e $62,8 \%$, respectivamente. Para o substrato vermiculita, a melhor temperatura foi a de $30^{\circ} \mathrm{C}$, com uma percentagem de germinação de $86,7 \%$, enquanto a temperatura de $25^{\circ} \mathrm{C}$ foi a que apresentou a menor germinação $(61,3 \%)$. Para a temperatura de $25{ }^{\circ} \mathrm{C}$ não houve diferença entre os substratos e para $30^{\circ} \mathrm{C}$ o melhor substrato é a vermiculita $(86,7 \%)$, comportamento repetido a $35^{\circ} \mathrm{C}(77,3 \%)$ (Tabela 2$)$.

De maneira geral, a temperatura de $30{ }^{\circ} \mathrm{C}$ com o substrato vermiculita proporcionou a maior percentagem de germinação, com $86,7 \%$ (Tabela 2).

Tabela 2. Porcentagem de germinação (\%G), índice de velocidade de germinação (IVG) e tempo médio (TM) de germinação das sementes de Sebastiania brasiliensis em diferentes substratos e temperaturas.

Table 2. Percentage of germination $(\% \mathrm{G})$, speed germination index (IVG) and germination average time (TM) of Sebastiania brasiliensis seeds in different substrates and temperatures.

\begin{tabular}{ccccccc}
\hline \multirow{2}{*}{ Temperatura } & \multicolumn{2}{c}{ \% G } & \multicolumn{2}{c}{ IVG } & \multicolumn{2}{c}{ TM } \\
\cline { 2 - 7 } & Areia & Vermiculita & Areia & Vermiculita & Areia & Vermiculita \\
\hline $25^{\circ} \mathrm{C}$ & $66,7 \mathrm{aA}$ & $61,3 \mathrm{cA}$ & $4,3 \mathrm{aA}$ & $4,9 \mathrm{bA}$ & $5,2 \mathrm{aA}$ & $3,4 \mathrm{bB}$ \\
$30^{\circ} \mathrm{C}$ & $62,7 \mathrm{aB}$ & $86,7 \mathrm{aA}$ & $3,7 \mathrm{aB}$ & $7,1 \mathrm{aA}$ & $5,3 \mathrm{aA}$ & $5,2 \mathrm{bA}$ \\
$35^{\circ} \mathrm{C}$ & $53,3 \mathrm{bB}$ & $77,3 \mathrm{bA}$ & $2,6 \mathrm{bA}$ & $4,3 \mathrm{bA}$ & $4,8 \mathrm{aB}$ & $7,1 \mathrm{aA}$ \\
\hline
\end{tabular}

Médias seguidas por letras distintas maiúsculas nas linhas e minúsculas nas colunas diferem entre si pelo teste de Tukey a 5\% de probabilidade.

Os maiores IVG encontrados para o substrato areia ocorreram nas temperaturas de $25^{\circ} \mathrm{C}$ e $30^{\circ} \mathrm{C}$, que não diferiram estatisticamente, com 4,3 e 3,7 , respectivamente. A vermiculita combinada com a temperatura de $30^{\circ} \mathrm{C}$ propiciou o maior IVG $(7,1)$, seguido pelas temperaturas de $25^{\circ} \mathrm{C}$ e $35^{\circ} \mathrm{C}$, estas não diferindo estatisticamente, com 4,9 para a primeira e 4,3 para a segunda (Tabela 2). De maneira geral, a temperatura de $30{ }^{\circ} \mathrm{C}$ com o substrato vermiculita apresentou o melhor IVG: 7,1 (Tabela 2).

O maior tempo médio (TM) encontrado para o substrato vermiculita foi na temperatura de $35^{\circ} \mathrm{C}$, com 7,1 dias de germinação, enquanto que a temperatura de $25^{\circ} \mathrm{C}$ foi a que apresentou o menor TM $(3,4)$, juntamente com a temperatura de $30^{\circ} \mathrm{C}(5,2)$, ambas não diferindo estatisticamente. Já para $\mathrm{o}$ substrato areia todas as médias foram iguais estatisticamente, com $4,8\left(35^{\circ} \mathrm{C}\right), 5,2\left(25^{\circ} \mathrm{C}\right)$ e $5,3\left(30^{\circ} \mathrm{C}\right)$ (Tabela 2). 
Para a temperatura de $25^{\circ} \mathrm{C}$, o maior TM é no substrato areia, com 5,2 dias de germinação. Para a temperatura de $30^{\circ} \mathrm{C}$, o TM não apresentou diferenças estatísticas entre os substratos. Por fim, na temperatura de $35^{\circ} \mathrm{C}$ obteve-se o maior TM no substrato vermiculita $(7,1)$, estatisticamente superior ao substrato areia, com 4,8 dias de germinação (Tabela 2).

Dentre todas as combinações testadas, o substrato vermiculita na temperatura de $30{ }^{\circ} \mathrm{C}$ apresentou a maior percentagem de germinação $(86,7 \%)$, seguido pelo mesmo substrato na temperatura de $35^{\circ} \mathrm{C}(77,3 \%)$. As menores médias ficaram para o substrato areia nas temperaturas de $30{ }^{\circ} \mathrm{C}(62,7 \%)$ e $35^{\circ} \mathrm{C}(53,3 \%)$.

Medeiros e Zanon (1998), trabalhando com diferentes temperaturas e substratos, identificaram que a melhor temperatura de germinação para Sebastiania commersoniana (Baill.) L. B. Sm. \& Downs (branquilho) foi $30{ }^{\circ} \mathrm{C}$, nos substratos papel em forma de rolo, papel filtro e vermiculita, sendo as porcentagens de germinação de $84,0 \%, 76,2 \%$ e $76,0 \%$, respectivamente. Embora o maior valor tenha sido no rolo de papel, não houve diferença estatística com as demais. Testando alternância de temperatura entre 20 e $30^{\circ} \mathrm{C}$ e temperatura constante de $25{ }^{\circ} \mathrm{C}$ na germinação do branquilho, Santos e Aguiar (2000) não encontraram diferença estatística na percentagem de germinação ao final do teste. Assim, o branquilho-leiteiro, por fazer parte muitas vezes da mesma região de ocorrência do branquilho, utilizar de métodos semelhantes de propagação de suas sementes (balistocoria) e pertencer ao mesmo gênero, demonstrou comportamento semelhante a Sebastiania commersoniana, apresentando melhor germinação na temperatura de $30{ }^{\circ} \mathrm{C}$.

Os melhores índices de velocidade de germinação foram observados no substrato vermiculita, na temperatura de $30^{\circ} \mathrm{C}(7,1)$. Santos e Aguiar (2000) obtiveram a melhor média de IVG na temperatura alternada $\left(20\right.$ e $\left.30^{\circ} \mathrm{C}\right)$, com o valor de 7,4 .

Avaliando todas as medidas germinativas, a combinação de vermiculita com temperatura de $30{ }^{\circ} \mathrm{C}$ foi a que apresentou maior percentagem de germinação, maior velocidade e um tempo médio intermediário aos outros tratamentos. Diversas espécies brasileiras também têm sua melhor germinação a $30^{\circ} \mathrm{C}$, como Caesalpinia ferrea Mart. ex Tul. (LIMA et al., 2006), Dalbergia nigra Fr. Allem. (ANDRADE, 2006), Sebastiania commersoniana (MEDEIROS; ZANON, 1998), Handroanthus roseo-albus (Ridl.) Mattos (STOCKMAN et al., 2007) e Parkia pendula (Willd.) Benth. ex Walp. (ROSSETO et al., 2009).

A dinâmica das florestas tropicais e os microclimas ali encontrados fazem dessas florestas ambientes que proporcionam variadas condições de adaptação. Por exemplo: as temperaturas próximas à superfície do solo podem variar bastante entre os ambientes, clareiras podem apresentar maiores amplitudes térmicas do que locais sombreados do sub-bosque, sendo um dos motivos de as temperaturas ótimas de germinação variarem entre $20^{\circ} \mathrm{C}$ e $30{ }^{\circ} \mathrm{C}$ (BORGES; RENA, 1993).

A espécie em estudo é classificada como heliófila e de luz difusa (LORENZI, 2002), o que leva a pressupor que possa germinar tanto em temperaturas mais elevadas (situação de pleno sol) como em situação de sombreamento, no interior do sub-bosque.

Neste trabalho, observou-se que em temperaturas menos elevadas a germinação ocorreu mais rapidamente do que na temperatura mais alta de $35^{\circ} \mathrm{C}$, não necessariamente germinando mais, fato este ocorrendo em temperaturas intermediárias. Espécies do mesmo ambiente apresentam temperaturas diferentes de germinação, como é o caso da aroeira-pimenteira (Schinus terebinthifolius Raddi), que teve sua melhor germinação em temperatura de $20^{\circ} \mathrm{C}$ (MEDEIROS; ZANON, 1998), enquanto Rego (2008), avaliando sementes de Blepharocalyx salicifolius, teve como melhores temperaturas de germinação $20^{\circ} \mathrm{C}$ e $25^{\circ} \mathrm{C}$.

Com relação aos substratos, a vermiculita proporcionou altas porcentagens de germinação e um maior vigor para Sebastiania brasiliensis. Ela é muito utilizada para testes de germinação de espécies florestais, gerando ótimos resultados, aliados à praticidade de manuseio (PIÑA-RODRIGUES; VIEIRA, 1988; PIÑARODRIGUES et al., 2004). Esse substrato propiciou, além da boa germinação, bom acamamento das sementes, uma vez que são sementes elipsoides, evitando-se o rolamento dentro das caixas (gerbox), devido à granulometria da vermiculita. Aliado a isso, Pacheco et al. (2006) e Pereira (1992) também verificaram que o substrato vermiculita permitiu um bom desempenho germinativo e não exigiu reumedecimento diário para Myracrodruom urundeuva Fr.All. Silva e Aguiar (2004) também obtiveram os melhores resultados de germinação em vermiculita para Cnidoscolus phyllacanthus (Müll. Arg.) Pax \& L. Hoffm.

Outra consideração importante a se fazer com relação ao substrato e à quantidade de água a utilizar refere-se às características ecológicas de cada espécie (OLIVEIRA et al., 1996). Para espécies com sementes de tamanho médio e grande e que ocorrem nas encostas úmidas e nas margens de rios, são recomendados substratos mais granulados e úmidos, como a vermiculita. Essa condição foi verificada 
neste estudo, já que Sebastiania brasiliensis ocorre naturalmente em solos úmidos e germinou melhor em vermiculita.

Observando a figura 4 , nota-se que a vermiculita à temperatura de $30{ }^{\circ} \mathrm{C}$ possibilita a germinação mais rápida, aumentando esse processo de $2 \%$ para $36 \%$ do terceiro para o quarto dia, e a $25^{\circ} \mathrm{C}$ aumentando de $1 \%$ para $25 \%$ do terceiro para o quarto dia. Em relação à vermiculita, o substrato areia retardou por um a dois dias a germinação, sendo que areia a $35{ }^{\circ} \mathrm{C}$ só iniciou a germinação no quarto dia, com maior expressão do quinto para o sexto dia.

A germinação começou a estabilizar no substrato vermiculita em $30{ }^{\circ} \mathrm{C}$ a partir do sétimo dia, e em $35{ }^{\circ} \mathrm{C}$ a partir do décimo dia. Nos tratamentos com areia, a estabilização ocorreu no nono dia. Portanto, observa-se que o tratamento com vermiculita a $30{ }^{\circ} \mathrm{C}$ atingiu sua máxima germinação em 10 dias (Figura 4). Por fim, a maior germinação acumulada foi em vermiculita a $30^{\circ} \mathrm{C}(86,7 \%)$, seguida pelo mesmo substrato a $35^{\circ} \mathrm{C}(77,3 \%)$ e areia a $25^{\circ} \mathrm{C}(66,7)$ (Figura 4).

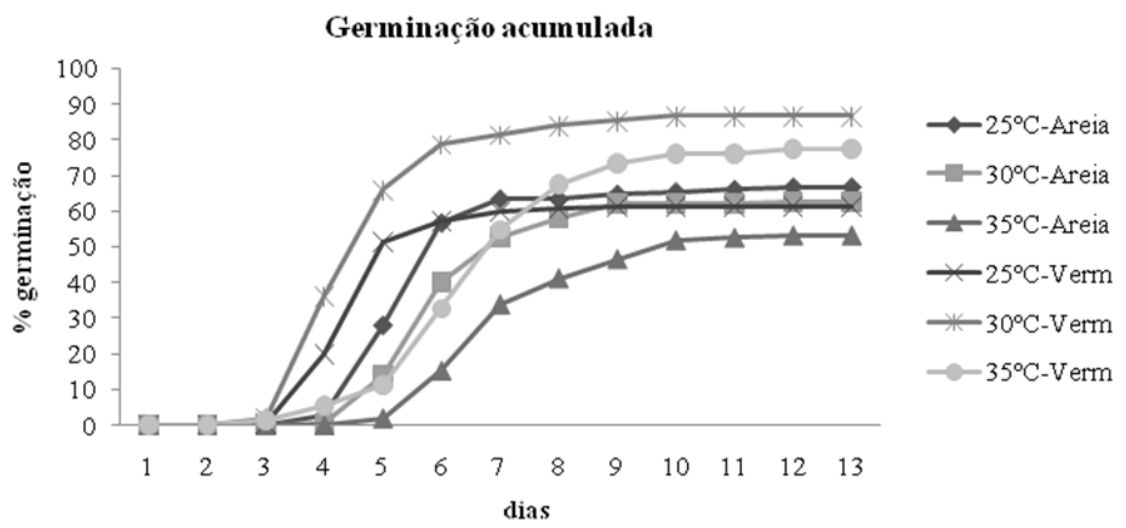

Figura 4. Porcentagem de germinação acumulada de sementes de Sebastiania brasiliensis nas diferentes temperaturas e substratos.

Figure 4. Percentage of accumulated germination of Sebastiania brasiliensis seeds in different temperatures and substrate.

\section{CONCLUSÕES}

- Fruto é do tipo cápsula tricoca, sendo cada coca subdividida em duas valvas (bivalvadas) contendo uma semente, abrindo-se quando maduro, com dispersão balistocórica.

- A semente possui forma elipsoide, coloração marrom-escura com pequenas manchas castanho-claras. É albuminosa, com reserva de lipídeo. O embrião é axial, foliáceo, espatulado.

- A germinação é do tipo fanerocotiledonar.

- Melhor percentual e índice de velocidade de germinação foi para as sementes submetidas à temperatura de $30^{\circ} \mathrm{C}$ e no substrato vermiculita.

- O menor tempo médio de germinação foi na temperatura de $25^{\circ} \mathrm{C}$ no substrato vermiculita.

- Nessas condições de avaliação, a contagem pode ser iniciada no segundo dia e finalizada após o $16^{\circ}$ dia.

\section{REFERÊNCIAS}

AMORIM, I. L. Morfologia de frutos, sementes, germinação, plântulas e mudas de espécies florestais da região de Lavras, MG. 127 f. Dissertação (Mestrado em Engenharia Florestal) Universidade Federal de Lavras, Lavras, 1996.

ANDRADE, A. C. S.; PEREIRA, T. S.; FERNANDES, M. J. Substrato, temperatura de germinação e desenvolvimento pós-seminal de sementes de Dalbergia nigra. Pesquisa Agropecuária Brasileira, Brasília, v. 41, n. 3, p. 517 - 523, 2006. 
BARROSO, G. M. Sistemática de angiospermas do Brasil. Viçosa: Universidade Federal de Viçosa, v. $2,1984.377 \mathrm{p}$.

BARROSO, G. M.; MORIM, M. P.; PEIXOTO, A. L.; ICHASO, C. L. F. Frutos e sementes: morfologia aplicada à sistemática de dicotiledôneas. Viçosa: UFV, 1999. 443 p.

BEWLEY, J. D.; BLACK, M. Seeds: Physiology of development and germination. 2 ed. New York: Plenum Press, 1994. 445 p.

BORGES, E. E. L.; RENA, A. B. Germinação de sementes. In: AGUIAR, I. B.; PIÑA-RODRIGUES, F. C. M.; FIGLIOLIA, M. B. Sementes florestais tropicais. Brasília: Abrates, 1993. p. 83 - 135.

BRASIL. Ministério da Agricultura, Pecuária e Abastecimento. Secretaria de Defesa Agropecuária. Regras para análise de sementes. Brasília, 2009. 399 p.

CARVALHO, N. M.; NAKAGAWA, J. Sementes: ciência, tecnologia e produção. Campinas: Fundação Cargill, 1983. 429 p.

COSMO, N. L.; GOGOSZ, A. M.; NOGUEIRA, A. C.; BONA, C.; KUNIYOSHI, Y. S. Morfologia do fruto, da semente e morfoanatomia da plântula de Vitex megapotamica (Spreng.) Moldenke (Lamiaceae). Acta Botânica Brasílica, v. 23, n. 2, p. 389 - 397, 2009.

COSMO, N. L.; NOGUEIRA, A. C.; LIMA, J. G.; KUNIYOSHI, Y. S. Morfologia de fruto, semente e plântula de Sebastiania commersoniana, Euphorbiaceae. Floresta, Curitiba, PR, v. 40, n. 2, p. 419 - 428, 2010.

FIGLIOLIA, M. B.; PIÑA-RODRIGUES, F. C. M. Considerações práticas sobre o teste de germinação. In: SILVA, A.; PIÑA-RODRIGUES, F. C. M.; FIGLIOLIA, M. B. (Coord.) Manual técnico de sementes florestais. São Paulo: Instituto Florestal, 1995. p. 45 - 59. (Série Registros, 14).

FIGLIOLIA, M. B; OLIVEIRA, E. C; PINÃ-RODRIGUES, F. C. M. Análise de sementes. In: AGUIAR, I. B.; PIÑA-RODRIGUES, F. C. M.; FIGLIOLIA, M. B. Sementes florestais tropicais. Brasília: ABRATES, 1993. p. 137 - 174.

GOGOSZ, A. M. Morfologia funcional de plântulas como indicador fisionômico da dinâmica de regeneração de espécies arbóreas da Floresta Ombrófila Mista, Paraná. 93 f. Tese (Doutorado em Ecologia e Conservação) - Universidade Federal do Paraná, Curitiba, 2013.

GOGOSZ, A. M.; COSMO, N. L.; BONA, C.; SOUZA, L A. Morfoanatomia da plântula de Campomanesia xanthocarpa O. Berg. (Myrtaceae). Acta Botanica Brasílica (Impresso), v. 24, p. 614 623, 2010.

HALISKI, S. L.; COSMO, N. L.; GOGOSZ, A. M.; REGO, S. S.; NOGUEIRA, A. C.; KUNIYOSHI, Y. S. Caracterização morfológica de frutos, sementes, plântulas e germinação de sementes de Casearia decandra. Pesquisa Florestal Brasileira (Impresso), v. 33, p. 253 - 259, 2013.

IBARRA-MANRÍQUEZ, G.; RAMOS, M. M.; OYAMA, K. Seedling functional types in a lowland rain forest in Mexico. American Journal of Botany, 88: 1801 - 1812. 2001.

KUNIYOSHI, Y. S. Morfologia da semente e da germinação de 25 espécies arbóreas de uma Floresta de Araucária. 233 f. Dissertação (Mestrado em Ciências Florestais) - Universidade Federal do Paraná, Curitiba, 1983.

LABORIAU, L. G. A germinação das sementes. Washington: Secretaria Geral da Organização dos Estados Americanos. 1983. 174 p.

LIMA JUNIOR, M. J. V. Manual de Procedimentos para Análise de Sementes Florestais. Manaus: UFAM. 2010. 146 p.

LIMA, J. D.; ALMEIDA, C. C.; DANTAS, V. A. V.; DA SILVA e SILVA, B. M.; MORAES, W. da S. M. Efeito da temperatura e do substrato na germinação de sementes de Caesalpinia ferrea Mart. ex Tul. (Leguminosae, Caesalpinoideae). Revista Árvore, Viçosa, v. 30, n. 4, p. 513 - 518, 2006. 
LORENZI, H. Árvores brasileiras: manual de identificação e cultivo de plantas arbóreas do Brasil. Nova Odessa: Instituto Plantarum, 2002, v. 2, ed. 2, 368 p.

MAGUIRE, J. D. Speed of germination aid in selection and evaluation for seedling emergence and vigor. Crop Science, Madison, v. 2, n. 2, p. 176 - 177, 1962.

MALAVASI, M. M. Germinação de sementes. In: PIÑA-RODRIGUES, F. C. M. Manual de análise de sementes florestais. Campinas: Fundação Cargill, 1988. p. 25 - 40.

MEDEIROS, A. C. S.; ZANON, A. Efeitos do substrato e da temperatura na germinação de sementes de branquilho (Sebastiania commersoniana (Baillon) L. B. Smith \& R. J. Down) e de pinheiro-bravo (Podocarpus lamberti Klotzch ex NDL). Boletim de Pesquisa Florestal, Colombo, 21 p. 1998.

OLIVEIRA, E. C.; PEREIRA, T. S. Euphorbiaceae: morfologia da germinação de algumas espécies. Revista Brasileira de Sementes, Brasília, v. 9, n. 1, p. 9 - 29, 1987.

OLIVEIRA, E. C.; PIÑA-RODRIGUES, F. C.; FIGLIOLIA, M. B. Propostas para a padronização de metodologias em análise de sementes florestais. Revista Brasileira de Sementes, Brasília, v. 11, n. 1 - 3, p. 1 - 42, 1996.

OLIVEIRA, O. Tecnologia de sementes florestais. Curitiba: Imprensa Universitária, 2007. 185 p.

PACHECO, M. V.; MATOS, V. P.; FERREIRA, R. L. C.; FELICIANO, A. L. P.; PINTO, K. M. S. Efeito de temperaturas e substratos na germinação de sementes de Myracrodruon urundeuva Fr. All. (Anacardiaceae). Revista Árvore, Viçosa, v. 30, n. 3, p. 359 - 367, 2006.

PEREIRA, T. S. Germinação de sementes de Bauhinia forficata Link. (Leguminosae Caesalpinoideae). Revista Brasileira de Sementes, Brasília, v. 14, n. 1, p. 77 - 82, 1992.

PIÑA-RODRIGUES, F. C. M.; FIGLIOLIA, M. B; PEIXOTO, M. C. Tecnologia de sementes: Testes de qualidade. In: FERREIRA, A. G.; BORGHETTI, F. Germinação - do básico ao aplicado. Porto Alegre: Artmed, 2004. p. 283 - 297.

PIÑA-RODRIGUES, F. C. M.; VIEIRA, J. D. Teste de germinação. In: PIÑA-RODRIGUES, F. C. M. Manual de análise de sementes florestais. Campinas: Fundação Cargill, 1988. p. 70 - 90.

POPINIGIS, F. Fisiologia de sementes. Brasília: AGIPLAN, 1977. 289 p.

REGO, S. S. Germinação, morfologia e sanidade de sementes de Blepharocalyx salicifolius (H.B.K.) Berg e Myrceugenia gertii Landrum - Myrtaceae. 113 f. Dissertação (Mestrado em Ciências Florestais) - Universidade Federal do Paraná, Curitiba, 2008.

REGO, S. S.; COSMO, N. L.; GOGOSZ, A. M.; KUNIYOSHI, Y. S.; NOGUEIRA, A. C. Caracterização morfológica e germinação de sementes de Curitiba prismatica (D. Legrand) Salywon \& Landrum. Revista Brasileira de Sementes (Impresso), v. 33, p. 616 - 625, 2011.

REITZ, R. Flora Ilustrada Catarinense - Euforbiáceas. Itajaí - Santa Catarina, 1988. 313 p.

RESSEL, K.; GUILHERME, F. A. G.; SCHIAVINI, I.; OLIVEIRA, P. E. Ecologia morfofuncional de plântulas de espécies arbóreas da Estação Ecológica do Panga, Uberlândia, Minas Gerais. Revista Brasileira de Botânica 27: 311 - 323. 2004.

RODERJAN, C. V. Morfologia do estágio juvenil de 24 espécies arbóreas de uma floresta com Araucária. 148 f. Dissertação (Mestrado em Ciências Florestais) - Universidade Federal do Paraná, Curitiba, 1983.

ROSSETO, J.; FIGUEIREDO e ALBUGUERQUE, M. C.; NETO, R. M.; SILVA, I. C. O. Germinação de sementes de Parkia pendula (Willd.) Benth. ex Walp. (FABACEAE) em diferentes temperaturas. Árvore, Viçosa, v. 33, n. 1, p. 47 - 55, 2009.

SANTOS, S. R. G.; AGUIAR, I. B. Germinação de sementes de branquilho (Sebastiania commersoniana (Baill.) Smith \& Downs) em função do substrato e do regime de temperatura. Revista Brasileira de Sementes, v. 22, n. 1, p. 120 - 126, 2000. 
SILVA, A.; FIGLIOLIA, M. B.; AGUIAR, I. B. Germinação de sementes de Acacia polyphylla DC. (monjoleiro) e de Aspidosperma ramiflorum müll. arg. (guatambu). Floresta, Curitiba, v. 37, n. 3, 2007.

SILVA, L. M. M.; AGUIAR, I. B. Efeito dos substratos e temperaturas na germinação de sementes de Cnidosculus phyllacanthus Pax \& K. Hoffm. (faveleira). Revista Brasileira de Sementes, v. 26, n. 1, p. 9 - 14, 2004.

STOCKMAN, A. L.; BRANCALION, P. H. S.; NOVEMBRE, A. D. L. C.; CHAMMA, H. M. C. P. Temperatura e substrato para a germinação de sementes de ipê-branco. Revista Brasileira de Sementes, v. 29, n. 3, p. 139 - 143, 2007.

TOLEDO, F. F.; MARCOS FILHO, J. Manual das sementes: tecnologia da produção. São Paulo: Ceres Agronômica, 1977. 224 p.

VELÁSQUEZ, J. C. Fisiologia de semillas y plántulas. Medellín: Universidad Nacional de Colômbia, 2002. $153 \mathrm{p}$.

VIDAL, W. N.; VIDAL, M. R. R. Botânica organografia: quadros sinóticos ilustrados de fanerógamos. Viçosa: UFV, 2003. 124 p.

VIEIRA, S. Estatística experimental. 2. ed. São Paulo: Atlas, 1999. 185 p.

VOGEL, E. F. Seedlings of dicotyledons: structure, development, types: descriptions of 150 woody Malesian taxa. Wageningen, Centre for Publishing and Documentation, 1980. 465 p.

WILLAN, R. L. Guia para la manipulacíon de semillas forestales con especial referencia a los trópicos. Roma: Estudio FAO Montes - Organizacion de las Naciones Unidas para la Agricultura y la Alimentación, 1991. 502 p.

WRIGHT, I. J.; CLIFFORD, H. T.; KIDSON, R.; REED, M. L.; RICE, B. L.; WESTOBY, M. A survey of seed and seedling characters in 1744 Australian dicotyledon species: cross-species trait correlations and correlated trait-shifts within evolutionary lineages. Biological Journal of the Linnean Society of London, 69: 521 - 547. 2000. 